\title{
Prevalence of irritable bowel syndrome to kimpesse, a rural urban city in democratic republic of Congo (DRC)
}

\author{
Abstract \\ Background : Irritable bowel syndrome(IBS) is the most commun functional gastro \\ intestinal disorder.
}

Aim : Determine the prevalence and the symptoms patterns of IBS in the rural urban community setting in DRC.

Materials and Methods : Questionnaires were administered to consenting individuals. Subjets satisfying the Rome III criteria of IBS were included.

Resultats : Out of 476 individuals, 28 adults had IBS (5.8\%). There were 14 males (50\%) and 14 females $(50 \%)$. The mean age was 31,4 years( $18-67$ years). $50 \%$ of them had IBS-C, $28.5 \%$ had IBS-D and $14,2 \%$ had IBS. The majority of IBS (+) $50 \%$ were in age group 18 27 years old.. IBS $(+)$ were highest in married group $57,1 \%$. The majority of IBS $(+) 75 \%$ had only one meal per day. There were $71,4 \%$ taking vegetables three times per week, 78,6 drinking only one glass of water daily, $25 \%$ smokers, 57,1 \% taking alcohol and 71,4 \% with spicy consumption. $50 \%$ of participants had 6 consultations through 6 months.

Conclusion: IBS is prevalent, the stress play a role to make up this disorder. The subtype C is more observed. Young adults are highly affected. IBS carry away medical consumption.
Volume 7 Issue 3 - 2017

\author{
Bomba DI Masuangi Emmanuel,' Mialabaka \\ Minawa Orphee, ${ }^{2}$ Nkondi Nsenga jacqueline ${ }^{3}$ \\ 'General Hospital of N' djili, Kinshasa Internal Medecine Service, \\ Congo \\ ${ }^{2}$ University of Kongo, Congo \\ ${ }^{3}$ University Hospital of Kinshasa, Internal Medicine Department, \\ Congo
}

Correspondence: Bomba DI Masuangi Emmanuel, General Hospital of N?djili, Kinshasa Internal Medecine Service, Congo, Tel (+243)815063710, Email bogibomba@gmail.com

Received: April 23, 2017 | Published: August 02, 2017

Keywords: irritable bowel syndrome, epidemiology

\section{Introduction}

Irritable bowel syndrome (IBS) is the most commun functional gastro intestinal disorder with a world wide prevalence ranging 7\%$21 \%{ }^{1}$ The diagnosis of IBS do not require diagnostic testing unless needed to exclude other diagnostic possibilities. IBS is characterised by presence of abdominal pain or discomfort associated with altered bowel ha bits. Although the Rome IV criteria already described, Rome III criteria that assess the relationship between abdominal pain or discomfort, stool form and change in bowel frequency are the most accepted criteria used in clinical practice for making a clinical diagnosis. Three clinical types have been recognized based on altered bowel motility and the resulting predominant feature : constipation predominant (C-IBS), diarrhea predominant (IBS-D) and IBS with mixed features of both diarrhea as well as constipation (M-IBS). ${ }^{2}$ women are at a slightly higher risk of IBS than man. ${ }^{1}$ Approximately two-thirds of IBS patients are female. ${ }^{3}$ IBS is most prevalent in patients 20 to 30 years old and decreases with age. ${ }^{1}$ In our country, Shindano at al carry out one study that reveal a prevalence of IBS ranged to $22,5 \%$ in urban area. ${ }^{4}$ The aim of this study was to determine the prevalence and the symptoms patterns of IBS in the rural urban community setting in DRC.

\section{Materials and methods}

Questionnaires were administered to consenting individuals. Subjets satisfying the Rome III criteria of IBS were included. The questionnaire was divided into three parts: The first part was designed to investigate individuals' socio-economic demographic data and patient characteristics as age, sex, marital status, education, occupation, number of regular meals per day, fiber consumption, spicy intake, daily water consumption, coffee consumption, alcohol consumption, smoking, direct costs(number of consultation per 6 months).

\section{Ethical considerations}

Aim of the research was explained to the participants. Informed consent from the participants was taken before starting the interview. The study was approved by the ethics committee of faculty of medicine, Kongo University (DRC) and has been performed in accordance with the ethical standards laid down in the 1964 Declaration of Helsinki.

\section{Results}

Out of 476 individuals, 28 adults had IBS (5.8\%). There were 14 males $(50 \%)$ and 14 females (50\%). The mean age was 31,4 years(18-67 years). $50 \%$ of them had IBS-C, $28.5 \%$ had IBS-D and $14,2 \%$ had IBS- M (Table1 ). The majority of IBS (+) $50 \%$ were in age group 18-27 years old (Table 2). IBS (+) were highest in married group $57,1 \%$ (Table 3 ). The majority of IBS $(+) 75 \%$ had only one meal per day (Table 4).There were $71,4 \%$ taking vegetables three times per week, 78,6 drinking only one glass of water daily, $25 \%$ smokers, $57,1 \%$ taking alcohol and $71,4 \%$ with spicy consumption (Table 5). 50\% of participants had 6 consultations through 6 months (Table 6).

Table I Sub types of IBS

\begin{tabular}{lll}
\hline Sub types & $\mathbf{N = 2 8}$ & $\%$ \\
\hline IBS-C & 14 & 50 \\
IBS-D & 8 & 28.57 \\
IBS-M & 4 & 14.29 \\
Unspecified IBS & 2 & 7.14 \\
Total & 28 & 100 \\
\hline
\end{tabular}


Table 2 Age groups

\begin{tabular}{lll}
\hline Age groups & $\mathbf{N}=\mathbf{2 8}$ & $\%$ \\
\hline Dec-27 & 14 & 50 \\
$28-37$ & 7 & 25 \\
$38-47$ & 4 & 14.2 \\
$48-57$ & 2 & 7.14 \\
Over 57 & 1 & 3.57 \\
Total & 28 & 100 \\
\hline
\end{tabular}

Table 3 Matrimonial status

\begin{tabular}{lll}
\hline Status & $\mathbf{N}=\mathbf{2 8}$ & $\%$ \\
Married & 18 & 57.14 \\
Single & 8 & 28.57 \\
Divorcee & 3 & 10.72 \\
Widower & 1 & 3.57 \\
Total & 28 & 100 \\
\hline
\end{tabular}

Table 4 Meal number per day

\begin{tabular}{lll}
\hline Number & $\mathbf{N}=\mathbf{2 8}$ & $\%$ \\
\hline $\mathrm{I}$ & $2 \mathrm{I}$ & 75 \\
2 & 5 & 17.86 \\
3 & 2 & 7.14 \\
More than 4 & 0 & 0 \\
Total & 28 & 100
\end{tabular}

Table 5 Eating habits

\begin{tabular}{lll}
\hline Alimony & $\mathbf{N}=\mathbf{2 8}$ & $\%$ \\
\hline Cassava Flour & & \\
-twice/week & 2 & 7.14 \\
-four time/week & 25 & 89.29 \\
-none time/week & $\mathrm{I}$ & 3.57 \\
Vegetables & & \\
-three time & 20 & 71.43 \\
-twice & 4 & 14.29 \\
-one time & 2 & 7.14 \\
-rarely & 2 & 7.14 \\
Rice & & \\
-twice/week & 18 & 64.28 \\
-four time/week & 4 & 21.43 \\
Fruits & & \\
-twice/week & 14 & 50 \\
-four time/week & 6 & 21.43 \\
-none time/week & 8 & 28.57 \\
Water & & \\
-one glass/day & 22 & 78.57 \\
>one glass/day & 6 & 21.43 \\
\hline & & \\
\hline
\end{tabular}

Table continued...

\begin{tabular}{lll}
\hline Alimony & $\mathbf{N}=\mathbf{2 8}$ & $\%$ \\
\hline Spicy & 20 & 71.43 \\
-yes & 8 & 28.57 \\
-no & & \\
Coffee & 17 & 60.71 \\
-yes & 11 & 39.29 \\
-no & & \\
Alcohol & 16 & 57.14 \\
-yes & 12 & 42.86 \\
-no & & \\
Tobacco & 7 & 25 \\
-yes & 21 & 75 \\
-no & & \\
Fizzy drink & 15 & 53.57 \\
-twice/week & 5.57 \\
-five time/week & 5 & 17.86 \\
-none & 8 & \\
\hline
\end{tabular}

Table 6 Number of medical consultations per year

\begin{tabular}{lll}
\hline Number & $\mathbf{N}=\mathbf{2 8}$ & $\%$ \\
\hline 0I-Mar & 4 & 14.29 \\
04-Jun & 10 & 35.72 \\
6 & 14 & 50 \\
Total & 28 & 100 \\
\hline
\end{tabular}

\section{Discussion}

In the present study, IBS prevalence of $5.8 \%$ was found. This prevalence is different from other studies. Another Congolese sample reported a prevalence of $22.5 \%$ using Rome III in an urban area. ${ }^{4}$ Lovell et al. ${ }^{1}$ range the worldwide prevalence between $7 \%$ to $21 \% .{ }^{1}$ Brandt reported that IBS affect approximately $5-20 \%$ of general population worldwide. The prevalence observed in present study appeared low. It is near the Asian prevalence (7\%). ${ }^{1}$ In Japanese study of medical and nursing students the prevalence of IBS was $35,5 \% .{ }^{5}$ Clearly, IBS prevalence vary across countries and depend on the diagnostic criteria used and type of study. The Rome III criteria are more used. Most IBS sufferers in this study had sub type $\mathrm{C}$ constipation. It seems paradoxical in population with high fiber consumption. It may be that the quantity of fiber taken is low and the low intake of water can contribute to this finding. Other published data reported most IBS sufferers had diarrhea predominant symptoms (IBS-D) ${ }^{6,7}$ The current study revealed that the IBS prevalence was higher in age group 18-27 years (50\%). Lovell et al. ${ }^{1}$ found that prevalence rates were highest among those aged 20-30 years and this prevalence decreases with age. ${ }^{1}$

The prevalence of IBS is significantly more common among women than men. Drossman reported that two- thirds of IBS patients are female. ${ }^{3}$ Ntagirabiri in Burundi observed that the prevalence of IBS is more high in female than men and the difference was statically significant. ${ }^{8}$ Our study found no difference between men and female. The sample was small. It can explain this finding. Food intolerance has been proposed as a potential cause of GI symptoms in some patients with IBS however this link is not well established. Although some patients associate onset of IBS symptoms with ingestion of 
particular foods identification of true food intolerance is challenging and elimination diets are typically time-consuming and difficult to implement. ${ }^{9}$ The present study does not analyzed the relationship between IBS and eating regular meals per day, insufficient fiber in diet, daily water consumption, smoking or alcohol consumption. Nevertheless, the predominant of subtype $\mathrm{C}$ can be explained by the the low number of regular meal, the low daily water consumption. ${ }^{10}$

\section{Conclusion}

IBS is prevalent, the stress play a role to make up this disorder. The subtype $\mathrm{C}$ is more observed. Young adults are highly affected. IBS carry away medical consumption. The results of the current study are important for directing our attention towards improving the quality of life of IBS patients in addition to symptomatic treatment.

\section{Acknowledgments}

None.

\section{Conflicts of interests}

None of the authors have a conflict of interests with any institution or organization.

\section{Funding}

None.

\section{References}

1. Lovell RM, Ford AC. Global prevalence of risk factors for irritable bowel syndrome: a meta-analysis. Clin Gastroenterol Hepatol. 2012;10(7):712-721.
2. Longstreth GF, Thompson WG, Chey WD, et al. Functional bowel disorders. Gastroenterology. 2006;130(5):1480-1491.

3. Drossman DA, Whitehead WE, Camilleri M. Irritable bowel syndrome: a technical review for practice guideline development. Gastroenterology. 1997;12(6):2120-2137.

4. Shindano T, Nkondi NJ, Kayembe P, et al. Le syndrome de l'intestin irritable à Kinshasa. Enquête menée dans 2 communes de Kinshasa. JGAF/Brazzaville. 2011

5. Okami Y, Kato T, Nin G, et al. Lifestyle and psychological factors related to irritable bowel syndrome in nursing and medical school students. $J$ Gastroenterol. 2011;46(12):14O3-1410.

6. Kanazawa M, Endo Y, Whitehead WE, et al. Patients and nonconsulters with irritable bowel syndrome reporting a parental history of bowel problems have more impaired psychological distress. Dig Dis Sci. 2004;49(6):1046-1053.

7. Adeyemo MA, Spiegel BM, Chang L. Meta-analysis: do irritable bowel syndrome symptoms vary between men and women? Aliment Pharmacol Ther. 2010;32(6):738-755.

8. Ntagirabiri R, Niyonzima S, Mumana-Burundi A. Syndrome de l'intestin irritable chez l'adulte jeune au Burundi. Médecine d'Afrique Noire n ${ }^{\circ} 6010$-octobre. 2013; pp.432-436

9. Foxx-Orenstein A. IBS--Review and What's New. Medscape General Medicine. 2006;8(3):20.

10. Brandt LJ, Chey WD, Foxx-Orenstein AE, et al.An evidence-based position statement on the management of irritable bowel syndrome. $\mathrm{Am}$ J Gastroenterol. 2009;104(1):S1-S35. 